\title{
DE LA HISTORIA DEL DERECHO A LA APROXIMACIÓN HISTÓRICA AL DERECHO: GAJES DE LA GLOBALIZACIÓN
}

\author{
FROM THE HISTORY OF THE LAW TO THE HISTORICAL \\ APPROACH TO THE LAW: PARTS OF GLOBALIZATION
}

\author{
Gabriela CRISTINA Cobo DEL Rosal PÉREZ \\ Universidad Rey Juan Carlos
}

Recibido: 04/12/2019 Aceptado: 18/12/2019

\section{RESUMEN}

La Historia del Derecho, al igual que el resto de las disciplinas jurídicas, se ha visto afectada por la globalización. Ello se ha concretado en su inscripción dentro el marco que ofrece una "Europa universitaria" auspiciada por el llamado "Proceso Bolonia”. Sabido es que el Derecho sólo puede ser entendido desde su perspectiva histórica, actualmente, ello debe recordarse con mayor énfasis. Además, resulta preciso se verifique desde su contexto histórico jurídico europeo. Todo lo cual favorece que la aproximación a la disciplina histórico jurídica se desarrolle cada vez más a través de su evidente virtualidad expansiva por irradiar su conocimiento a todas las esferas del saber jurídico. Se plantea de este modo una Historia del Derecho Europeo como complemento, ahora imprescindible, para el buen conocimiento no solamente de la disciplina histórico jurídica española sino de las ciencias jurídicas en general.

Palabras clave: Historia del Derecho Europeo, Europa Universitaria, Proceso Bolonia, Saber jurídico. 
ABSTRACT

History of Law as the rest of juridical subjects has been affected by the effects of the globalization. That fact has been executed through the inclusion of the subject in the reality provided by an "Universitarian Europe" funded by the so called "Bologna Process". It is well known that Law can only be understood through its historical perspective but nowadays that fact needs to be specially remembered and it requires to be done from a European legal historical perspective. All which favours the approach to the studies of History of Law tends to be done through its obvious expansive virtuality since its knowledge radiates other spheres of juridical knowledge. Therefore, a consideration of a European History of Law as a complement for the historical approach to Spanish Law turns out to be ineluctable not only to achieve a better knowledge in Legal History but to achieve it in general legal sciences.

Keywords: History of European Law, University Europe, Bologna Process, Legal knowledge.

Sumario: 1. Introducción. 2. Los visigodos o la utilidad del conocimiento inútil: 2.1. Los resultados como los nuevos medidores del saber; 2.2. La decisiva formación histórica en los grandes juristas. 3. Historia y globalización jurídica: 3.1. De la historia de las fuentes a las fuentes de la historia. 3.2. Staying hungry \& staying foolish.

A Manuel Luzón Domingo

\section{INTRODUCCIÓN}

"Vivimos tiempos difíciles en los que el cultivo de las ciencias puras sin aplicaciones utilitarias -y evidentemente la Historia del Derecho es una de ellas- tropieza cada vez más con el despego de la juventud estudiosa"1.

Las palabras del insigne Alfonso García-Gallo sancionadas en 1953 actualmente adquieren renovada vigencia. Desde un punto de vista pragmático el cultivo de la vida intelectual y espiritual parecen actividades de

\footnotetext{
1 Alfonso García-Gallo, "Historia, Derecho e Historia del Derecho", Anuario de Historia del Derecho Español 23 (1953): 19.
} 
poca o, más bien, nula utilidad reservadas exclusivamente a aquellos eruditos o raros de la sociedad a los cuales su desarrollo les satisface más que otras ${ }^{2}$.

Resulta evidente que el cultivo de determinadas ramas del saber como el arte, la filosofía o la literatura, a primera vista, puede parecer carente de utilidad práctica, productiva o de ambas. Lo dicho se hace más evidente si uno se empeña en buscar en su desarrollo una potencial utilidad o carácter práctico a corto plazo o en el marco de lo estadísticamente previsible. En esta sentido seguramente no fueron parámetros netamente prácticos, los que impulsaron a Sócrates a dialogar con Platón, a San Agustín a regalar a la humanidad sus confesiones más íntimas, a Cervantes a ensoñar molinos, a Lope de Vega a despertar la unidad, a Mozart a coronar la noche, a Beethoven a darle un himno a la paz, a Velázquez a asomarse en el regio espejo o, a Van Gogh, a cegar el azaroso siglo XIX con sus girasoles. Son tan solo algunos ejemplos especialmente elocuentes del propósito de la presente reflexión pues afortunadamente la lista es innumerable. Y es que seguramente a ninguno de ellos les impulsó a desarrollar sus virtuosos intelectos un espíritu exclusivamente práctico y, sin embargo, sin su obra no entenderíamos gran parte del acervo de la cultura occidental. Ello probablemente fue así más allá de si su "productividad" respondía a un deseo de reconocimiento, a encargos, o a posibles remuneraciones pactadas. Cabe destacar como mera curiosidad además que tal rasgo que a día de hoy se podría catalogar como "poco práctico" se evidenció en muchas de sus sonadas elecciones vitales. De ello da cuenta la lectura de sus biografías que, en ocasiones,

2 Abraham Flexner destina un muy interesante trabajo a la utilidad del conocimiento inútil y explica cómo Marconi no habría sido capaz de crear una radio sin los descubrimientos previos llevados a cabo por el profesor universitario Clerk Maxwell, quien en 1865 destinó sus esfuerzos a realizar operaciones de cálculos hasta entonces imposibles y, en principio, sin utilidad práctica alguna en el campo de la electromagnética, que quedaron publicados en 1873. Marconi en gran medida, interpreta Flexner, lo que hizo fue rematar el final de una ardua tarea llevada a cabo por sus precursores en el desarrollo de una teoría aparentemente inútil hasta el punto de haber sido considerado solamente como el inteligente inventor movido meramente por la utilidad. Abraham Flexner, The usefulnees of useless knowledge (Harper's, Octubre 1939), 544-545, acceso el 20 de octubre de 2019, https://library.ias.edu/files/UsefulnessHarpers.pdf última visita. 
demuestra con pasmosa dureza cómo pagaron muchas de las consecuencias de su falta de visión práctica. Evidentemente no se trata de fomentar una actitud irresponsable, que favorezca el fracaso, que nos aleje de la sociabilidad y de la felicidad. Sin embargo, si puede resultar bueno y muy práctico a la larga observar a los sabios y de ellos extraer lo que verdaderamente pueda favorecer el mejor desarrollo de nuestras capacidades.

Sorprende más recientemente en un campo eminentemente práctico como lo es el de las conocidas "nuevas tecnologías" que Steve Jobs utilizó criterios poco prácticos para orientar su propia formación académica. Y es que, como él mismo reconocería, rechazó voluntariamente la posibilidad de obtener una titulación universitaria, lo cual como sabemos, no fue obstáculo para que revolucionara la tecnología informática desde que creara Apple.

Naturalmente no se trata de animar a los estudiantes a abandonar sus estudios universitarios, pero lo cierto es que en sus comienzos Steve Jobs tomó caminos de dudosa utilidad práctica como reconocería él mismo en su seductor discurso para los graduados de la Universidad de Stanford pronunciado el 12 de junio de 2005. Admitió en él que abandonó la Universidad al poco de matricularse para comenzar a asistir a las asignaturas que verdaderamente le apasionaban siguiendo exclusivamente su curiosidad y su intuición. Por ello se matriculó en caligrafía sin albergar la más remota esperanza de que aquella formación tuviera siquiera alguna aplicación práctica. Pero diez años después, cuando diseñó el primer ordenador Macintosh, utilizó aquella caligrafía y la incluyó en los conocidos ordenadores Mac. Steve Jobs afirmó además que posteriormente Windows imitó a Mac con lo que, de no haber sido por aquel conocimiento aparentemente inútil que adquirió en aquellos cursos caligrafía, los ordenadores de hoy en día seguramente no ofrecerían una tipografía tan variada ${ }^{3}$.

3 Así lo reconoce en su discurso de graduación pronunciado en la Universidad de Standford en 2005. https://www.youtube.com/watch?v=HHkJEz_HdTg acceso el 20 de octubre 2019. 
Centrados en la disciplina histórico jurídica, sin duda, fueron más que meritorios los esfuerzos de la Escuela Histórica del Derecho a lo largo del siglo XIX. A ellos se debe que la disciplina alcanzara el tratamiento de científica. La esencial sensibilidad que aporta la visión histórica capaz de observar el Derecho como algo "cambiante" contribuyó a que alcanzara su autonomía científica. Se celebraba de este modo su "puesta de largo", en expresión de García-Gallo, a la cual todos los juristas fueron invitados ${ }^{4}$.

Actualmente corresponde a la Historia del Derecho renovarse para incluir los nuevos factores que han afectado a la cambiante realidad social conocida como la knowledge society. En esta dirección cobran nuevamente vigencia las propuestas metodológicas visionarias en su momento auspiciadas principalmente por Paul Koschaker. A través de ellas se reclamaba un mayor uso del método comparado y su aplicación. Ello resulta eficaz para el estudio comparado entre las distintas naciones desde la visión conjunta que ofrece Europa. Así mismo también propone la extensión de tal metodología a lo largo del tiempo para contrastar una realidad vigente con su realidad análoga pretérita. Se trata en suma de una aproximación metodológica que parte del enfoque que ofrece observar la disciplina en su perspectiva europea. El cual, entre otras enriquecedoras aportaciones, hace gala de la virtualidad expansiva de la Historia del Derecho pues su conocimiento irradia a todas las demás ramas del saber jurídico.

Y es que al igual que ha ocurrido con el resto de las disciplinas jurídicas la Historia del Derecho se ha visto afectada por el paso del tiempo y la globalización. Lo cual se evidencia en la nueva realidad que ofrece la "Europa universitaria" abanderada por el conocido como "Proceso Bolonia”. Todo ello ha favorecido que la aproximación a la disciplina histórico jurídica tienda cada vez más a verificarse a través de su virtualidad expansiva la cual, hasta ahora, ha tendido a mantenerse excesivamente

4 Francisco Tomás y Valiente, Manual de Historia del Derecho español (Madrid: Tecnos, 1979), 36. 
contenida al ámbito nacional. Tal rasgo expansivo que, en muchos aspectos singulariza la disciplina histórico jurídica, resulta ahora clave a fin de plantear los nuevos enfoques que, sin prescindir de los ya existentes, alcance mayor interés para los juristas en su primera formación.

Ello se traduce en una necesaria adecuación del método docente al interés del actual estudiante de Derecho sin disminuir su carácter científico. Pues la Historia del Derecho no debe solamente instruir al jurista en ciernes a través de una serie de datos. Datos por demás ahora más accesibles que en tiempos de la Escuela Histórica. La Historia del Derecho debe formarle más eficazmente de modo que permita al incipiente jurista llegar a comprender por qué el Derecho actual es cómo es, e incluso, cómo podría éste ser de otra forma. Esto no es nada nuevo o no debería serlo pues así se lo planteaba ya García-Gallo. Y es que la Historia del Derecho es una "ciencia en formación" que ofrece el único camino para la comprensión de la "esencia del Derecho" cuyo objetivo fundamental radica en estudiar la vida del mismo a lo largo del tiempo ${ }^{6}$.

Resulta innegable que para comprender el tiempo de hoy es preciso interpelar al pasado. Sin embargo, se reclama una renovación metodológica como medicina preventiva a fin de no perder el interés del estudiante de Derecho. Y es que no es nuevo decir que el jurista que supera al técnico se forja, entre otras, pero fundamentalmente, a través de una sólida formación histórico jurídica. Si los juristas del futuro carecen de la tal formación la sociedad se resentirá notablemente y la rectificación se producirá de forma inevitable, pero evidentemente, no sin un coste ${ }^{7}$.

5 Galo Sánchez, Curso de Historia del Derecho. Apuntes (Madrid: Reus, 1975), 15. También Rafael Gibert, "Concepto de la Historia del Derecho español", Anuario de la Facultad de Derecho. Universidad de Extremadura 4 (1986): 310.

6 José Manuel Pérez-Prendes Muñoz-Arraco, Historia del Derecho Español, Vol. 1 (Madrid: Universidad Complutense de Madrid, 2004): 19.

7 En este sentido Vid., Fernando de Arvizu y Galárraga, "La enseñanza de la Historia del Derecho: reflexiones en busca de una polémica”, A.H.D.E. 58 (1988): 498. 


\section{LOS VISIGODOS O LA UTILIDAD DEL CONOCIMIENTO INÚTIL}

\subsection{LOS RESULTADOS COMO LOS NUEVOS MEDIDORES DEL SABER}

En una realidad como la actual donde la información sobreabunda y donde la inmediatez se ha convertido en sinónimo de eficacia y, por lo tanto, de utilidad, el cultivo de la Historia General y de la Historia del Derecho en concreto parece no tener a primera vista gran utilidad práctica. Habida cuenta de tal aparente carencia podría deducirse que su presencia en un Grado como Derecho resulta ser “conocimiento inútil” y del que podría o, incluso, debería prescindirse.

Lo cierto es que el estudiante del siglo XXI en sus estudios de primer curso en el Grado de Derecho puede necesitar, ahora incluso más que antes, entender desde el principio la conveniencia y utilidad práctica de esta disciplina y reclamar la justificación de su poco práctica existencia. Y, lo que es más importante, puede que si no le encuentra una utilidad pronto pierda el interés en su formación histórico jurídica por completo. $Y$ es que el perfil del estudiante actual ha cambiado mucho.

A tal exacto y sin ánimo de simplificar, generalizar o reducir al extremo la compleja realidad social del estudiante actual puede ser útil tratar de describir ciertos parámetros en los que suele desenvolverse y que necesariamente deben tenerse en cuenta a la hora de acondicionar el método docente a la necesidad de a quién va éste dirigido. Puede decirse que el actual estudiante con mayor frecuencia es un estudiante bilingüe o tendente al bilingüismo. Por lo general está familiarizado con el desarrollo de actividades de aprendizaje en formatos intensivos que proponen un aprendizaje veloz, ya sea de idiomas, de recursos tecnológicos o de deportes. Normalmente llega al aula con información de última hora sobre acontecimientos acaecidos en las antípodas de donde cursa sus estudios. En un cada vez más elevado porcentaje realizará uno de los cursos del Grado en el extranjero. Además, tiene grandes probabilidades de realizar un Máster especializado en la que será su futura profesión, la cual 
desarrollará en un marco abrumadoramente competitivo. Todo ello le motiva y le estresa. Generalmente tiene prisa. No es infrecuente que las notas descritas afecten, al menos una, sino todas, a un mismo estudiante.

Sin embargo, si se trata de un estudiante en un Doble Grado las posibilidades de darse todas ellas en el mismo estudiante encuentra una proporción mayor incrementando probablemente aún más su necesidad de focalizar todo su esfuerzo en lograr adquirir una formación que le convierta lo antes posible en un profesional competitivo. A todo ello debe añadirse que se trata de un estudiante en parte estresado por la inmediatez de las comunicaciones, del marketing y de la información, al cual le motiva estar constantemente seguro de que no pierde el tiempo. Sin querer generalizar, es probable haya crecido en un entorno proclive a cultivar la creencia en que se pueden medir asiduamente los resultados concretos de los esfuerzos por él realizados y además puede partir de la idea de que el conocimiento científico se puede adquirir de una forma mucho más veloz de la real. Por todo ello es probable que el ritmo del aprendizaje profundo le desmotive inicialmente si el docente no está alerta. No es que rechace un aprendizaje profundo. En absoluto, lo sigue queriendo, valorando, incluso exigiendo tal vez con más encono que en el pasado. Sin embargo, ahora necesita venga acompasado de un método docente capaz de mantener su interés y que le asegure que no pierde el tiempo. $Y$ si a todo ello se añade, que de tanto en cuanto, se le adelante información acerca de su posible utilidad práctica, mucho mejor.

$\mathrm{Si}$ en este contexto revisamos el que normalmente suele ser el tercer bloque temático de todos los manuales de la disciplina, el Derecho visigodo, el estudiante de primero de Derecho podría y, tal vez incluso, debería plantearse para qué le sirve o en qué medida dicho conocimiento le convertirá en un mejor jurista. Por todos es sabido que los estudiantes de primero de Derecho escucharán bellas y contundentes afirmaciones como que durante el reino visigodo por vez primera se hizo presente en la Historia de la Península Ibérica un poder jurídico-político entendido como "específicamente hispano" conformándose entonces una entidad 
política independiente, en palabras de Pérez-Prendes. Conocerá que la desaparición de su reino sito en Toledo se verificó en una sola jornada del caluroso julio andaluz del año 711, en el que se extinguió súbitamente su poder ante el predominio del islamismo ${ }^{8}$. Sin embargo, a pesar de ello, sabrá que su sociedad y su Derecho no se extinguirían tan fácilmente y su rastro será fundamental en el desarrollo y mejor comprensión del posterior Derecho, así como de su evolución ${ }^{9}$. Todo ello lo escuchará en clase el estudiante de Derecho. Le asegurarán además que es preciso tenerlo presente a la hora de aproximarnos a entender aspectos muy concretos de la idiosincrasia jurídica europea actual. Tanto es así que Franz Wieacker sintetizó su importancia diciendo que el pensamiento jurídico europeo encuentra sus raíces en las "las tres últimas fuerzas básicas del mundo antiguo": el Imperium, el Cristianismo y "la nueva conciencia vital de los pueblos y razas que se apoderaron del territorio del Imperio romano de occidente o fueron afectados por su cultura jurídica o conquistados por ella". Y consideró que "Cada uno de estos elementos aportó contribuciones insustituibles a la cultura jurídica europea (...)”10.

Efectivamente al incipiente jurista todo ello puede resultarle por momentos interesante. Sin embargo, pronto podría preguntarse en qué medida dicho conocimiento se materializará en un resultado concreto, por ejemplo, en su incorporación en los nominados a los premios "Forbes abogados”. Y lamentablemente para él lo cierto es que la utilidad práctica del conocimiento histórico jurídico concreto no puede ponderarse. Tampoco puede evaluarse a través de unos datos reducibles a algoritmos cuyo resultado final mida exactamente la productividad o la eficacia de un abogado en ejercicio o de un juez a través de un estudio comparado que, además, evidencie las diferencias de su eficacia y productividad con los de otro jurista o juez que desconoce el Derecho propio del reino visigodo

8 José Orlandis, Historia de España. La España Visigoda (Madrid: Gredos, 1977); La vida en España en tiempo de los godos (Madrid: Rialp, 1991).

9 Pérez-Prendes, Historia del Derecho..., 264.

10 Franz Wieacker, Historia del Derecho privado de la Edad Moderna (Granada: Comares, 2000), 17. 
de Toledo. Ello porque la ponderación concreta de los beneficios de dicho saber es básicamente imposible.

Si creyéramos que se puede responder concretamente al grado de "utilidad" o de "eficacia", que una perspectiva histórica pueda ofrecer al jurista en su formación, y pudiéramos dar una respuesta absolutamente acertada, rápida, breve y eficaz, quebraríamos aquella consideración tan brillantemente expuesta por el gran jurista Jaime Guasp. Y es que entendía Guasp que el conocimiento universitario debe aspirar a obtener una dimensión "radicalmente absoluta" de los problemas y no conformarse con contemplaciones parciales. De modo que es recomendable, en suma, un estudio extensivo frente a uno intensivo en el que no debiera éste dar un paso hasta que no dominara un tema. El aprendizaje en Derecho es y debe ser interesado, selectivo, extenso, total e incondicional ${ }^{11}$. Todo lo cual en el caso concreto del estudio de la disciplina histórico jurídica cobra especial importancia pues irradia ésta los efectos de su conocimiento a las restantes disciplinas en una suerte de virtualidad expansiva. De modo que la Historia del Derecho resulta ser esencial en la formación del jurista $^{12}$.

Si quisiéramos responder de algún modo al estudiante de Derecho que se interpele en torno a la importancia práctica del concreto conocimiento que ofrece la disciplina habría que acudir a medidores cuyos datos no son reducibles a algoritmos exactos que demuestren su concreta utilidad. Por ejemplo, se podría acudir a Víctor Hugo poeta, dramaturgo y novelista del siglo XIX y a su célebre afirmación por todos conocida, "quien abre una escuela cierra una prisión". $\mathrm{O}$ a Marc Bloch historiador y copartícipe de la creación de la Revista Annales d histoire économique et sociele quien desde su cautiverio a manos de los nazis redactó una obra en la que se interrogaba a sí mismo acerca del sentido de la educación en

11 Jaime Guasp, "Como debe estudiarse el Derecho", Anales de la Universidad de Murcia 16/3-4 (1957-1958): 175; 176.

12 José Antonio Escudero, "Derecho y tiempo: dogmática y dogmáticos", Anuario de Historia del Derecho Español 40 (1970): 273. 
Historia concluyendo que concedía ésta a la formación un "color verdadero" ${ }^{13}$. Y es que abrir una escuela implica una transformación profunda y lenta de la sociedad que puede traducirse efectivamente en cerrar una prisión. Sin embargo, los efectos de su presencia serán absolutamente impredecibles, pero con seguridad éstos llegarán.

En todo caso parece preciso adecuar la ciencia y su difusión al momento que vivimos a fin de salvar la distancia entre el necesario y lento reposo que la incorporación de nuevos conocimientos implica con el ritmo de la vertiginosa realidad social en la que se encuentra inmerso el estudiante de primero de Derecho. Y todo ello evidentemente debe realizarse sin mermar en modo alguno su carácter científico. En los tiempos actuales las palabras de José Ortega y Gasset al decir que "la vida es prisa" cobran especial significación y parece haber una tendencia a que los resultados de buena parte de los aspectos formativos universitarios deban evidenciarse de forma inmediata ${ }^{14}$. Es importante especialmente ahora recordar a los estudiantes los beneficios del saber así como alertar al jurista en su primera formación de las nefastas consecuencias de un saber superficial o puramente técnico ${ }^{15}$.

Es posible que para ello resulte eficaz un adecuado recurso de la tecnología utilizada con prudencia. Ello por ser ésta una herramienta con la que el estudiante actual se siente completamente familiarizado la cual además es capaz de agilizar, facilitar y estimular el conocimiento. Llegados a este punto no parece preciso elaborar un panegírico en torno a las ventajas, beneficios y facilidades que han traído las nuevas tecnologías al desarrollo y promoción de las ciencias en general pues las mismas son del todo punto imponderables. Solamente alertamos al lector que la interpretación de la próxima reflexión debe realizarse en el marco del

13 Marc Bloch, Introducción a la Historia (Madrid: Fondo de Cultura Económica, 1992), 12.

14 José Ortega y Gasset, Historia como sistema (Madrid: Revista de Occidente, 1966), 20.

15 "El abuso de la técnica, es decir, la producción o aplicación moralmente injusta de las fuerzas naturales con los medios de una técnica (que, como tal, ni es buena ni mala), ha creado condiciones de convivencia humana encaminadas contra el hombre. Una de las consecuencias de este abuso fue el nacimiento de un $<<$ mundo de masas $>>$ ". Wieacker, Historia del Derecho..., 558. 
reconocimiento sincero y agradecido a los incontables beneficios que el desarrollo de las tecnologías ha traído a la ciencia en general. Pues de lo que se trata ahora es de proteger y favorecer una sólida formación y evitar promocionar un aprendizaje banal y superficial en el universitario general y en el jurista en concreto. $Y$ es que el uso de la tecnología como recurso promotor del conocimiento científico debe verificarse con la cautela señalada. Se alertaba de ello a mediados del pasado siglo desde la Universidad de Harvard cuando comenzaron a desarrollarse los primeros ordenadores desde donde se denunciaban ya entonces los posibles efectos nocivos de su mal uso. Así lo hizo Peter Drucker, decisivo autor en materia de gestión empresarial moderna, quien los llegó a considerar como auténticos “morons" o “tontos”. Recordaba la necesidad de enfocar su uso de manera equilibrada pues podían éstos llegar a ahogar el ingenio y observaba en cambio en las graves carencias de los ordenadores el verdadero estímulo para el ingenio ${ }^{16}$. En este sentido Steve Jobs entendía los ordenadores como "una bicicleta para la mente". Efectivamente ese es el criterio más recomendable, entenderlos como un mecanismo que estimule su acción cerebral y no al contrario ${ }^{17}$.

Se atribuye a Picasso la reflexión por la cual el maestro de la pintura consideraba que los ordenadores no eran útiles porque solamente daban respuestas. Seguramente se refería a que éstos sólo proporcionaban datos concretos en la línea irreflexiva de un ordenador. Y es que lo cierto es que una de las funciones principales de la Universidad reside en formular preguntas y no necesariamente en ofrecer respuestas. Ello porque es oficio del docente estimular el espíritu crítico y enseñar al estudiante a elaborar sus propias respuestas. Esta reflexión no es novedosa pues ya desde la Antigua Grecia el método Socrático se basó en la curiosidad. Cabe decirse que buena parte de los grandes avances científicos se suscitan por la mera satisfacción de su curiosidad y probablemente la

16 Peter Drucker, The Effective Executive (London: Editorial Advisers, 1967), 162.

17 https://www.youtube.com/watch?v=ob_GX50Za6c, acceso el 20 noviembre 2019. 
sospecha de una ulterior utilidad práctica podría haber mermado dicha curiosidad $^{18}$.

En gran medida fue una pregunta la que inspiraría el movimiento por el cual surgió la primera Universidad en Occidente tal y como la entendemos hoy. Se trataba de una pregunta que probablemente había quitado el sueño a más de un monarca alto medieval. ¿Cómo hicieron los romanos de la Edad Antigua para orquestar la dirección de un gobierno de proporciones territoriales tan extensas, capaz de acoger realidades políticas y culturales tan dispares de forma tan altamente eficaz y durante tanto tiempo? La solución a tantas noches de insomnio parecía tocar a su fin cuando Irnerio redescubre el Corpus Iuris Civilis. En este momento los inquietos aspirantes a juristas ansiosos por responder a tal regia cuestión y por descubrir el modelo romano con el interno propósito de desarrollar para la Baja Edad Media fórmulas de gobierno más eficaces que las planteadas por el sistema feudal, viajaron a Bolonia para conocer el Derecho romano. Y de este modo surgen las primeras Universidades en Europa como las entendemos hoy día.

De modo que parece que lo práctico verdaderamente es que las instituciones destinadas al conocimiento cultiven y fomenten la curiosi$\operatorname{dad}^{19}$. La Universidad no debe responder exclusivamente a curiosidades concretas que se podrían resolver fácilmente a través de una rápida consulta enciclopédica o a través de una o varias búsquedas en internet. El universitario en general y el jurista en formación concretamente debe conocer al concluir sus estudios universitarios cómo alcanzar sus propias respuestas a fin de construirse un espíritu crítico que, respetuoso con el criterio de los demás, sea capaz de contribuir a construir realidades mejores.

En todo caso es importante alertar que, a fin de evitar caer en la tentación de entender que si "La vida es prisa y necesita con urgencia saber

18 Flexner, The usefulnees..., 545.546.

19 "Institutions of learning should be devoted to the cultivation of curiosity", Flexner, The usefulnees..., 545 . 
a qué atenerse y es preciso hacer de esta urgencia el método de la verdad (...)" terminemos por entender como "Verdad lo que ahora es verdad, y no lo que se va a descubrir en un futuro indeterminado" ${ }^{20}$. Es por ello que a la larga seguramente sea muy "eficaz" saber bien desde qué criterio filosófico iniciamos nuestro camino universitario a fin de no dejarnos llevar por la corriente ${ }^{21}$.

Sin querer desanimar al incipiente jurista que preocupado por su formación precisa reclama una única respuesta, rápida y concreta a sus preguntas debe añadirse que muchas de ellas tienen incontables respuestas. Sin ir más lejos así ocurre con el propio concepto de Derecho. Para satisfacer en algo esta concreta curiosidad se puede arrojar una posible respuesta, tal vez imprecisa, pero, como poco muy elegante, extraída de la pluma de Rafael Gibert al decir que no deja el concepto de Derecho de existir por el hecho de que la doctrina aún no haya encontrado un único concepto $^{22}$.

Finalmente, si de dar respuestas concretas a la eficacia del saber histórico jurídico se trata podría decirse que, como mínimo, le aumentará al jurista el campo de visión de la realidad y le ayudará a reconocer más hábilmente la excelencia en su profesión. Y es que la Historia del Derecho puede comportarse como unas gafas ajustadas para identificar la excelencia del jurista y desechar la vulgaridad descrita por Gilbert Keith Chesterton por la cual uno puede ver pasar la excelencia y no reconocerla.

\footnotetext{
20 Ortega y Gasset, Historia como..., 20.

21 La obra ya clásica de Rafael Gambra resulta especialmente eficaz en este sentido, Historia sencilla de la Filosofía, 29 $\mathrm{a}$ ed. (Madrid: Rialp, 2014).

22 "La falta de unanimidad de los autores acerca de lo que es el Derecho se opone sólo aparentemente a la existencia de un concepto general del mismo". Gibert, "Concepto...", 314. Las presentes páginas nacen esencialmente de las reflexiones que tratan este asunto como Tomás y Valiente, Manual...., 34.35, y Bruno Aguilera Barchet, Historia y Derecho, Manual de iniciación. I (Barcelona: Hurope, 1999), 43.44. También del mismo autor, Estado y Derecho en España. Un ensayo de historia comparada. I. Las bases: de los orígenes al año 711 (Madrid-París: Instituto de Estudios Jurídicos Internacionales, 2010), 13.14.
} 


\subsection{LA DECISIVA FORMACIÓN HISTÓRICA EN LOS GRANDES JURISTAS ${ }^{\mathbf{2 3}}$}

"La incomprensión del presente nace fatalmente de la ignorancia del pasado" ${ }^{24}$. Es por ello que muchos profesores de Historia del Derecho acuden al aula conectados virtualmente a un periódico o dispuestos a comentar una noticia reciente desde la enriquecedora perspectiva que ofrece la visión del pasado jurídico. Tal era el caso de Gibert quien al menos en los años en que como emérito visitaba las aulas de la Universidad lo hacía acompañado de su periódico dispuesto a integrar en sus lecciones las noticias del día. Y es que se servía Gibert de esa inmediata utilidad que ofrece la disciplina como "saludable escuela de relativización"25.

Qué duda cabe que las sucesivas generaciones incorporan algo al "edificio del Derecho" ${ }^{26}$. Es por ello especialmente preciso que deba cuidarse con especial encono que la excesiva especialización a la que ahora se tiende no imponga un excesivo desconocimiento en los restantes órdenes del saber a través de la frecuente soberbia de los "especialistas" denunciada por Ortega y Gasset ${ }^{27}$. Y es que el jurista reclama un pensamiento "a propósito del Derecho" para no convertirse en un técnico de

23 Actualmente parece debemos recordar con mayor énfasis la importancia de la ciencia iushistórica en un sentido general como lo es el que afecta a la formación educativa general dentro del marco de las ciencias vinculadas a las Humanidades así como su significación más tradicional, como lo es su perspectiva como parte de los estudios jurídicos en que sigue estando presente. Ello lo hacemos a continuación teniendo presente una orientación que se encamina a la aproximación al Derecho histórico desde un prisma comparado al hilo del proceso de integración europea. Todo lo cual sin duda alguna se puede inscribir manteniendo presente el criterio de Escudero en torno al carácter de la disciplina histórico jurídica según el cual entendemos es éste "eminentemente formativo genérico", y, "como todo lo sustancial" "resiste los deslindes clasificatorios". Escudero, "Derecho y tiempo...", 273.

24 Bloch, Introducción..., 22.

25 Tomás y Valiente, Manual..., 34.

26 Juan B. Vallet de Goytisolo, Estudios sobre fuentes del Derecho y método jurídico (Madrid: Montecorvo, 1982), 885 .

27 En palabras de Ortega y Gasset "Desde el siglo X no ha habido etapa histórica en que Europa poseyese menos sensibilidad y saber filosóficos que en los cincuenta últimos años del siglo XIX. Esto ha producido el caos mental que ahora, con sorpresa, encuentra el europeo dentro de sí. Y es que la cultura de los especialistas crea una forma específica de incultura más grande que otras alguna. Nadie entienda que yo ataco al especialismo en lo que tiene de tal; indudablemente uno de los imperativos de la ciencia es la progresiva especialización de su cultivo. Pero obedecer este solo imperativo es acarrear a la postre el estancamiento de la ciencia y por un rodeo inesperado implantar una nueva forma de barbarie. La ignorancia del que es por completo ignorante toma un cariz pasivo e inocuo. Pero el que es un buen ingeniero o un buen médico y sabe mucho de una cosa no se determinará a confesar su perfecto desconocimiento de las demás. Transportará el sentimiento dominador que, al andar por su especialidad, experimenta a los temas que ignore”. Ortega y Gasset, Historia..., 150.151. 
las normas vigentes cuyo funcionamiento conocen y aplican de forma mecánica $^{28}$.

Es por todo ello que a la hora de abogar a favor de la Historia del Derecho, como parece actualmente obligado requisito para justificar la presencia o permanencia de la disciplina en el Grado de Derecho, resulta elocuente acudir a juristas de otras especialidades de reconocido prestigio que, en el ejercicio de su actividad, observaron en la Historia del Derecho la verdadera esencia en la formación del buen jurista ${ }^{29}$. Y es que no debemos olvidar que éste ha sido el general proceder en todas las disciplinas jurídicas hasta aproximadamente las dos décadas anteriores al cambio de siglo. Como elocuente ejemplo sirva la rama del Derecho penal por ser especialmente sensible y evidente su carácter práctico pues como sabemos se trata de la única rama del ordenamiento jurídico con capacidad para limitar uno de los principales Derechos Fundamentales como lo es la libertad.

Resulta cuando menos sorprendente que si uno revisa los trabajos de los más destacados penalistas del siglo XIX y principios del XX, las introducciones históricas de sus principales obras no suelen constituir un apartado introductorio manido compuesto por pocas páginas sino, más bien, todo lo contrario. Normalmente destinan en ellas un importante espacio de su estudio, a veces incluso, tomos enteros quedan reservados a la parte histórica. Ello por entender que comprender bien los orígenes y la evolución de las distintas y complejas instituciones o categorías penales resulta algo imprescindible para la más adecuada práctica penal. De tal modo que son jueces, abogados en ejercicio y fiscales los

28 Francisco Tomás y Valiente, Manual..., p. 34. Wieacker lo dirá de forma categórica la Historia del Derecho es "(....) expresión respecto a la existencia del Derecho en las profundidades del pasado que puede preservar, tanto a los juristas investigadores como a los estudiosos, de ser unos meros técnicos y rutinarios que sacrifiquen el espíritu viviente del Derecho al mandato de un poder ajeno al Derecho, o a los muertos principios doctrinales de una dogmática de escuela” Wieacker, Historia..., Prólogo del autor, 1.

29 Por ejemplo, Pedro Gómez de la Serna, Prolegómenos del Derecho (Madrid: Librería de Sánchez, 1887), 160. 
que en sus actividades investigadoras redactan estudios de cientos de páginas destinados a la Historia del Derecho

Cabe destacar que un destacado sector de la doctrina penal española inscrito en escuelas científicas bien diferenciadas e incluso encontradas en sus postulados doctrinales, encuentran en la Historia del Derecho el común acervo jurídico desde el cual la ciencia penal debía nutrirse. Así se observa, sin ánimo alguno de exhaustividad, en las obras de Juan del Rosal $^{30}$, Luis Jiménez de Asúa ${ }^{31}$, José Antón Oneca ${ }^{32}$, Eugenio Cuello Calón ${ }^{33}$, Quintiliano Saldaña ${ }^{34}$, José R. Casabó ${ }^{35}$ o Gonzalo Rodríguez Mourillo ${ }^{36}$ por citar tan sólo algunos significativos ejemplos.

Significativo ejemplo de ello lo constituye la actividad desarrollada por el Fiscal en ejercicio Manuel Luzón Domingo en 1960 quien a través de su Tratado de la culpabilidad se convierte en el valedor de la disciplina histórico jurídica. Valedor en lo que de cuestionable pueda ésta tener, tanto por la vexata quaestio en cuanto al carácter histórico o jurídico de la misma, como en cuanto a la utilidad de la disciplina. Y es que el profesor Luzón seguramente no consideraría que su actividad pudiera parcelarse tanto $\mathrm{y}$, sin medir las actuales y por demás artificiales

30 En sentido similar se responde Juan Del Rosal al preguntarse por la esencia del Derecho J., Tratado de Derecho penal, Parte General, Vol. 1 (Madrid: Imprenta Aguirre, 1968), 53.

31 Muy especialmente en su Tratado de Derecho penal (Buenos Aires: Losada, 1950).

32 Quien dedicaría buena parte de su actividad a comprender el Derecho penal desde la perspectiva histórico jurídica con trabajos de incuestionable valía como "Los antecedentes del nuevo Código penal", Revista General de Legislación y Jurisprudencia, Editorial Reus, $\mathrm{n}^{0} 154$ (1929); "Los proyectos decimonónicos para la reforma del Código penal español", Anuario de Derecho penal y Ciencias penales, $\mathrm{n}^{\circ} \mathrm{XXV}$ (1972); "Los fines de la pena según los penalistas de la Ilustración”, Revista de Estudios Penitenciarios (1964); "Los proyectos decimonónicos para la reforma del Código penal español", Anuario de Derecho penal y Ciencias penales 25 (1972) entre otras.

33 Especialmente en su manual de la Derecho penal dedica una buena parte del mismo a una aproximación histórica de gran valor, Derecho Penal, Parte General, Vol. I (Barcelona: 1980).

34 Especialmente en su "Historia del Derecho penal", publicado como Apéndice al Tratado de Derecho penal de Franz Von Liszt, Vol. I, traducción $18^{a}$, ed. alemana (Madrid: 1914).

35 El cual se doctoraría con un tema de enfoque esencialmente histórico jurídico que prosperaría en importantes publicaciones como por ejemplo "Los orígenes de la codificación penal en España; el plan del Código criminal de 1787”, Anuario de Derecho Penal 22 (1969): 313-340.

36 Quien igualmente se doctoraría en 1959 con una tesis que sigue un enfoque histórico jurídico como lo fue la destinada al Hurto y robo en el Derecho español de la que resultaría una importante publicación en la disciplina histórico jurídica como lo sería "La distinción hurto-robo en el derecho histórico español", A.H.D.E. 32 (1962): 25-112. 
fronteras que separan al docente del investigador, o, al jurista del historiador, actuaría como lo que era, nada menos que un jurista 37.

Luzón quería realizar simplemente una breve investigación a fin de comprender exactamente la compleja cuestión de la culpabilidad y, presa de su prurito profesional, admitiría él mismo que no se supo frenar a tiempo, y daría lugar a un Tratado de la Culpabilidad y de la culpa penal, Con especial referencia a los delitos de imprudencia que aún hoy es obligado punto de partida a la hora de tratar de la culpabilidad desde una perspectiva histórica.

Estos casos concretos exclusivamente referidos al ámbito penal constituyen tan sólo un ejemplo pues son incontables los casos de juristas de todas las especialidades que encuentran en la Historia del Derecho un pilar de su saber. Como ejemplo de ello, el Catedrático de Derecho Administrativo Alejandro Nieto en sus frecuentes introducciones históricas ofrece una muy generosa aproximación histórico jurídica a los temas que trata ${ }^{8}$. Actualmente dicha actividad de parte de los juristas está en declive si la comparamos con el pasado siglo, sin embargo, un sector importante de la actual doctrina jurídica sigue dedicando parte de su actividad investigadora a ofrecer en sus estudios importantes aproximaciones históricas que, sin duda, enriquecen su perspectiva. Por citar sólo algún ejemplo especialmente significativo a este respecto y continuando en el campo del Derecho Administrativo, debe citarse la obra de Juan Ramón Fernández Torres39.

37 El también Fiscal Antonio Quintano Ripollés diría de Luzón que se trataba de "un jurista de raza" que redactaría dicha obra "en la euforia de una envidiable juventud", Antonio Quintano Ripollés, "Luzón Domingo, Tratado de la culpabilidad y de la culpa penal", Anuario de Derecho Penal y Ciencias Penales 3 (1960): 505.

38 Como en el caso de su obra El arbitrio judicial (Barcelona: Ariel, 2000). Otros ejemplos de sus publicaciones más elaborados bajo este enfoque enfoque metodológico lo son "El derecho como límite del poder en la Edad Media”, Revista de Administración Pública 91 (1980): 7-74; o Mendizábal: apogeo y crisis del progresismo civil: historia política de las cortes constituyentes de 1836-1837 (Barcelona: Ariel, 2011).

39 Juan Ramón Fernández Torres, La formación histórica de la jurisdicción contenciosoadministrativa (1845-1868) (Madrid: Civitas, 1998); Historia legal de la jurisdicción contenciosoadministrativa (1845-1998) (Madrid: Iustel, 2007). 


\section{HISTORIA Y GLOBALIZACIÓN JURÍDICA}

\subsection{DE LA HiSTORIA DE LAS FUENTES A LAS FUENTES DE LA HISTORIA}

A la hora de formar a los nuevos juristas existen, en términos generales, dos claras aproximaciones. La que ofrece el mundo anglosajón vinculada al "Common Law" que aproxima al estudiante desde el principio de sus estudios universitarios a su práctica al margen de las construcciones abstractas. Y una segunda propia de los conocidos como "Sistemas jurídicos de Derecho civil” en la que por la presencia directa de la influencia romana reconstruida a partir de la Baja Edad Media favorecería el sistema de aprendizaje netamente teórico ${ }^{40}$.

En España en las Facultades de Derecho el tipo de enseñanza tradicionalmente impartido ha sido por lo general el segundo, esto es, el "teórico-científico”. A pesar del nuevo planteamiento del legislador que proponía incentivar más la atención en los aspectos docentes dicha realidad no se logró erradicar y el excesivo dogmatismo se evidenciaba en las aulas universitarias españolas de los años setenta, ochenta y noventa como un rasgo característico en las carreras de humanidades. Tal actitud sería duramente criticada por la doctrina del momento. El abuso de una aproximación racional o dogmática era significativamente más acusado en aquellas materias especialmente vinculadas a la realidad del ejercicio del Derecho. Y también ya entonces autores como Helmut Coing recordaron el carácter empírico de la disciplina histórico jurídica cuyo soporte sostenían lo encuentra en las fuentes ${ }^{41}$.

Adelantándose ya a un posible problema alertaba la doctrina en general del cuidado que debía observarse para evitar un posible desequilibrio a favor de una excesiva aproximación práctica. También la doctrina prevendría al docente de la posibilidad de formar "leguleyos" frente a

\footnotetext{
40 Ello a pesar de la histórica especial sensibilidad de los romanos a la "técnica de la elaboración del Derecho por la vía del caso práctico”, Manuel Jesús García Garrido y Francisco Eugenio, Estudios de Derecho y Formación de Juristas (Madrid: Dykinson, 1988), 43, nota 13.

41 Helmut Coing, Las tareas del historiador del Derecho. Reflexiones metodológicas, trad. A. Merchan (Sevilla: Publicaciones de la Universidad de Sevilla, 1977), 30.31.
} 
juristas, observando la diferencia entre ambos en que los primeros "saben leyes" y los segundos saben "interpretarlas al conocer el Derecho en su formación y fundamentos históricos y científicos" 42 . Actualmente ambos métodos docentes tratan de integrarse intentando evitar caer en un excesivo empirismo 43 a fin de evitar avocar en el conocido "bluesky law" $" 4$.

El posible actual desequilibrio entre una aproximación racional o dogmática frente a la aproximación empírica tal vez pueda deberse a una reacción contraria a la actitud tan despreocupada que en materia docente en sus aspectos metodológicos docentes y pedagógicos vino siendo desarrollada en la práctica docente de la Universidad. Especialmente dicha despreocupación fue denunciada en los referidos años ochenta y noventa por autores como Juan Ramón Capella o Fernando de Arvizu quienes estaban alertados de la "escasa valoración y preocupación por las cuestiones didácticas” por parte del profesorado universitario ${ }^{45}$. Además, en el pasado, el silencio por parte del legislador en cuanto al alumno y a los métodos docentes había sido la tónica. En este sentido Luis Sánchez Agesta escoraba la responsabilidad en el profesorado al decir que “(...) aunque algo pueda ayudar, no creo que las reformas de la enseñanza puedan realizarse desde la ley; en general, son obra de una lenta evolución impulsada esencialmente por la iniciativa misma de quienes participan en las tareas docentes" ${ }^{6}$. Sin embargo dicha línea de pensamiento no ha sido precisamente la seguida por el legislador el cual insiste a través de distintas vías en el desarrollo de los aspectos docentes del profesor

\footnotetext{
42 Manuel García y Eugenio, Estudios..., 25. También Juan Ramón Capella Hernández, "La crisis actual de la enseñanza del derecho en España". En La enseñanza del Derecho. Seminario de Profesores de la Facultad de Derecho, dir. por Juan José Gil Cremades (Zaragoza: Institución Fernando el Católico, 1985), 42.

43 Preocupados por ello, García y Eugenio dirá que “(...) una enseñanza con objetivos únicamente prácticos no es auténticamente universitaria”, Estudios..., 23. También Aguilera, Historia..,, 12-13. 44 Se trata de un término anglosajón entendido como el "lejano cielo azul de los conceptos" en el cual no se debe anclar el profesor.

45 Ilustrativas del momento previo a la reforma son las páginas de Juan Ramón Capella Hernández, "La enseñanza...", 23-42. Fernando de Arvizu y Galarraga, "La enseñanza de la Historia del Derecho: reflexiones en busca de una polémica", Anuario de Historia del Derecho Español 58 (1988): 494. 46 Luis Sánchez Agesta, "La Universidad y la enseñanza del Derecho", Arbor (1950): 232.
} 
universitario. La insistencia del legislador, la oficial preocupación planteada desde Bolonia en este sentido, sumado al esfuerzo de muchos profesores porque su curso no sea impartido meramente a través clases teóricas, han contribuido en gran medida a cambiar la situación anteriormente descrita ${ }^{47}$.

Sin embargo, cualquier avance metodológico docente que suponga una mayor calidad en la transmisión de conocimiento a los estudiantes pierde efectividad si no se encuentra con un profesorado motivado. Las palabras de Arvizu ante el revuelo que suscitó el debate en torno al mantenimiento de la disciplina como troncal en la antigua Licenciatura de Derecho invitaban a los Historiadores del Derecho a que se replantearan sus tareas "como enseñantes" así como su "capacidad de comunicar conocimientos, y la necesidad de que éstos sirvan a la formación de los juristas en ciernes" ${ }^{48}$. Y es que el profesor debe mantener presente de forma constante la idea de estimular intelectualmente al alumno. Ello a fin de contribuir a la formación de aquellos "juristas con ingenio" de los que hablaría Manuel Calvo García, entendidos como aquellos que obtienen "una formación metodológica adecuada para desarrollar su ejercicio profesional con el dominio de recursos técnicos y argumentarios que les permita aplicar el Derecho de una manera más flexible y adecuada a las exigencias del caso" ${ }^{\prime 4}$.

Interesados por estimular el apetito del alumno en el caso de la disciplina histórico jurídica parece debe permanecer presente la idea del

47 Actualmente de los planteamientos del "Proceso Bolonia" y del E.E.E.S. se deduce un enfoque metodológico en el que, como anteriormente apuntábamos, el profesor está invitado a ejercer sus facultades docentes como, corrientemente se empieza considerar, un gestor del conocimiento, un habilitador o facilitador del aprendizaje. Por su parte la participación del alumno cobra oficialmente o se incita a que tenga un papel activo. Sin embargo, dicha bondad metodológica había sido planteada ya por los docentes con anterioridad, es más, casi podría decirse que desde siempre. De una enseñanza activa en la que el alumno se implique preparando con antelación las clases a partir de la estructura planteada por el profesor ya hablaba por ejemplo Witker en los tan criticados años setenta de la Universidad. El cual plantea una enseñanza activa que para su desarrollo necesariamente debía estar en conexión con la investigación jurídica, Jorge Witker, La enseñanza del Derecho (México: Editora Nacional, 1975), 102 ss., también 152.

48 Arvizu, "La enseñanza de la Historia del Derecho...", 496.

49 Manuel Calvo García, Interpretación y argumentación jurídica. Trabajos del Seminario de Metodología Jurídica, Vol. I (Zaragoza: Prensas de la Universidad de Zaragoza, 200o), 8. 
carácter relativo de la norma. Pues es sabido que los frecuentes cambios en la legislación y en la jurisprudencia puede provocar en muchas materias que lo que se aprende un día no tenga validez al siguiente. En este sentido García y Eugenio dirán que "Los profesores de las asignaturas más actualizadas, y que las defienden a ultranza como las más progresistas, no se dan cuenta de que en realidad enseñan Historia del Derecho, porque en unos años será historia la información que están transmitiendo" 50 . Todo ello con la finalidad de fomentar en los estudiantes la idea por la que se dice que "bellas son las cosas que se ven, más bellas las que se saben, pero las más bellas de todas son las que se ignoran"51.

La enseñanza puede y debe ser alegre y viva pues sin duda son los mejores reclamos en el interés del estudiante ${ }^{52}$. Y es que lo fundamental de la actividad docente no reside en los datos que se tratan de transmitir y mucho menos en los actuales tiempos, lo fundamental reside en la actitud vital que se les quiera transmitir ${ }^{53}$. El principal fin de la enseñanza se encuentra en la formación de un criterio, en la construcción de una potencia de comprensión así como de una conducta54. Como decía ya Miguel de Unamuno en su discurso de apertura del curso académico 19001901 en la Universidad de Salamanca, “(...) deber es del maestro en una disciplina cualquiera inspirar afición a ella en sus discípulos, hacerles amar su estudio" ${ }^{55}$.

50 García y Eugenio, Estudios..., 21.

51 "Pulchra quae videntur, pulchriora quae sciuntur, longre pulcherrima quae ignorantur". Se trata las palabras dichas por Niels Stensen, "un danés del siglo XVII a quien se deben hallazgos importantes en el ámbito de la anatomía humana y la cristalografía" citadas por el Premio Nobel de Física Isidoro Rasines, Supermateriales 1996, Nuevas Revistas, 48 (dic. 1996-enero 1997) 115 y que llegan recogidas por Rafael Navarro Valls, "Principios éticos y responsabilidad en el ejercicio de la función docente", en La Universidad y las profesiones jurídicas. Deontología, Función Social y Responsabilidad (Madrid: Fundación Central Hispano, 1998), 113, nota 12 bis.

52 Citando a Juan Ramón Jiménez. Cfr. Lorenzo Martín-Retortillo Baquer, "Acerca de la enseñanza de la Ciencia del Derecho Administrativo", Seminario de Profesores de la Facultad de Derecho, dirigido por J.J. Gil Cremades (Zaragoza: 1985), 174.

53 Guasp, "Como debe estudiarse...", D-173.

54 Sánchez Agesta, "La Universidad...", 223.

55 Cfr. Martín-Retortillo, "Acerca de...”, 173 donde recuerda las palabras de Unamuno. Es desde este prisma por el que se propone fomentar la actitud curiosa y crítica en el alumno vale la pena tener presentes las sugerencias que Guasp, en una conferencia pronunciada en el Aula Magna de la Facultad de Derecho de Murcia en la festividad de San Raimundo de Peñafort, les ofrecería a los estudiantes en cuanto a cómo se debe estudiar Derecho. En síntesis planteaba Guasp que la actividad del estudiante 
A tal exacto las palabras de Juan Ramón Jiménez si bien las refiere al entorno de los maestros y sus discípulos son perfectamente extrapolables al ámbito docente universitario general:

“(...) el acuerdo es muy importante en la relación entre discípulo y maestro, ya que tanto se cultiva el maestro explicando, como el discípulo oyendo. La unidad de avance entre maestro y discípulo es el secreto más pródigo de la enseñanza. Si no existe esa unidad, poca ilusión puede haber en uno ni en otro; y si no hay ilusión en ellos, la enseñanza y el aprendizaje no existen. La ilusión, la alegría, la ambición, el amor son necesarios para la enseñanza correspondida y sin esas fuentes no es posible que despierte una vocación, ni es posible continuarla si se ha encontrado" ${ }^{\prime 56}$.

Incluso llegaría a decir:

“(...) me atrevería a decir que es mucho más importante en una Universidad, despertar también ilusión en un discípulo, que exigirle perfección en los estudios que está practicando (...)" ${ }^{57}$.

\subsection{STAYING HUNGRY \& STAYING FOOLISH ${ }^{58}$}

Mantenerse alerta, curioso y expectante es la actitud propuesta. No parece preciso abordar en las presentes páginas la vexata quaestio ${ }^{59}$

debía ser "interesada". Ello porque entiende que no se produce un auténtico saber sin interés. Recuerda que el auténtico aprendizaje es el que es "activo" y que necesita el estímulo que proporciona el interés. El alumno debe ser "selectivo" a la hora de escoger tanto en los textos como en las explicaciones dadas lo que mejor respondan al espíritu de enseñanza al que estén avocados. Guasp, "Como debe estudiarse...”, D-174. En este sentido es especialmente explícito Guasp al decir que “(...) la posición de la segunda enseñanza, en que poco más o menos vamos llevados de la mano por nuestros maestros que nos acotan problemas y soluciones, al entrar por las puertas de la Universidad tiene que ser cambiada radicalmente", sostiene que el alumno debe ser "radicalmente selectivo", D-175.

56 Cfr. Martín-Retortillo, "Acerca de...", 173-174.

57 Martín-Retortillo, “Acerca de...", 174.

58 Así finaliza el estimulante discurso de Steve Jobs en el discurso de Graduación en la Universidad de Stanford anteriormente citado. Ut Supra nota 3.

59 José Manuel Pérez-Prendes, Curso de Historia del Derecho Español (Madrid: Universidad Complutense, 1989), 179. Al plantearse una aproximación científica a la disciplina histórico jurídica surge el tradicional debate en torno a la adscripción de la disciplina a la Historia o al Derecho el cual no vamos a abordar aquí. Sin embargo es importante recordar que, por más antiguo que pueda resultar dicho debate, su estudio resulta enriquecedor a fin de plantear una adscripción metodológica En este sentido S. de Dios dirá que "Una vez conocidas las distintas tendencias histórico-jurídicas y analizadas las críticas de sus detractores, estaremos en mejores condiciones de proponer la orientación histórico- 
considerada por algunos de "tautológica" ${ }^{60}$ en torno a la adscripción de la Historia del Derecho a la Historia o al mundo jurídico ni a su concepto y objeto. Sin embargo, lo cierto es que si se trata de extender su objeto superando el plano estatal como plantean los postulados del Derecho Europeo se debe concretar claramente desde qué punto se parte.

La inscripción de la Historia del Derecho en la esfera de la Historia General o en la del mundo jurídico, como sabemos, implica necesariamente aceptar su carácter dual. Término utilizado por Escudero probablemente por su significado más conciliador que el carácter bifronte del que hablara Jesús Lalinde Abadía ${ }^{61}$ pues resulta consustancial a la disciplina histórico jurídica ${ }^{62}$. Un carácter dual que no enfrenta ambas cien$\operatorname{cias}^{63}$.

Lo cierto es que la realidad del estudiante de Derecho y del estudiante universitario en general ha cambiado radicalmente desde los tiempos en que García-Gallo expresara su preocupación en torno al poco interés de la disciplina para los estudiantes ${ }^{64}$.

El universitario actual desarrolla su actividad en el marco de una Europa institucional de la cual es ciudadano y cuya integración es, como sostienen algunos "milagrosa" e "irreversible"65. El citado universitario, como ya se dijo, es bilingüe o tiende vertiginosamente a serlo y forma

jurídica que creemos más aceptable". Salustiano de Dios, "El Derecho y la realidad social: reflexiones en torno a la Historia de las Instituciones", Historia, Instituciones y Documentos 3 (1976): 191.

6o Gustavo Villapalos, Prólogo a Bruno Aguilera Barchet, Introducción jurídica a la Historia del Derecho, $2^{\mathrm{a}}$ ed. (Madrid: Civitas, 1996), 16. En sentido parecido Bruno Aguilera Barchet, "Reflexiones sobre el concepto de Historia del Derecho", Anuario de la Facultad de Derecho. Universidad de Extremadura 9 (1991) 328.

61 Jesús Lalinde Abadía, "Hacia una Historia paralógica del Derecho", Historia, Instituciones, Documentos 4 (1977): 317-353, 319-325.

62 Escudero, "Entendemos en fin que la Historia del Derecho es Historia, y como ciencia es histórica y jurídica. Y mejor que bifronte, como postula Lalinde, es decir, de dos caras o frentes, se nos antoja una ciencia intrínsecamente dual", Curso de Historia del Derecho, Fuentes e Instituciones Políticoadministrativas (Madrid: Edisofer, 2003), 40.

63 En este sentido, algunos entienden que el enfrentamiento entre el Derecho y la Historia verdaderamente carece de un "sentido real" ello por entender que ambas ramas del saber no constituyen "categorías irreductibles", Aguilera, "Reflexiones...", 328.

64 Palabras con las que iniciábamos la presente reflexión. Ut supra, nota 1.

65 Bruno Aguilera, Entre Estado y Nación. Sociedad, poder y derecho de la prehistoria a la integración europea (París: Instituto de Estudios Internacionales, 2011), 444. 
parte protagonista de la que se ha considerado como la knowledge society ${ }^{66}$ concretada especialmente a través de la "Europa universitaria" esencialmente abanderada por la Declaración de Bolonia ${ }^{67}$.

En este contexto a la Historia del Derecho, como le ha ocurrido al resto de las disciplinas científicas, también le han afectado los nuevos factores que han terminado por alterar decisivamente la realidad y la forma de aproximarnos al saber en general. Concretamente en la disciplina histórica jurídica actual se observa que los factores de "europeidad" y "globalización" han incrementado la tendencia en la aproximación a la disciplina histórico jurídica a verificarse a través de la virtualidad expansiva de la misma. Este carácter expansivo siempre ha singularizado a la Historia del Derecho, sin embargo, hasta ahora había tendido a mantenerse en gran medida contenido como anteriormente apuntábamos. Dicha virtualidad expansiva se posiciona ahora como un factor fundamental a la hora de proponer y desarrollar nuevos enfoques metodológicos integradores y no excluyentes que, sin prescindir de los tradicionalmente empleados, se muestran adecuados a los tiempos actuales y además resultan probablemente por ese mismo motivo muy atractivos para el actual jurista en su formación.

Llegados a este punto las palabras de Sánchez Agesta resultan adecuadas a la hora de tratar de explicar lo recientemente expuesto al decir que las innovaciones radicales pueden ocasionar "más daño por lo que destruyen que provecho con lo que construyen" 68 . Por ello insistimos en el carácter continuista la presente propuesta metodológica aquí planteada, la cual encontró su principal valedor Koschaker ${ }^{69}$.

66 Peter Drucker, "Knowledge-Worker Productivity: The Biggest Challenge", California Management Review 41, no 2 (1999): 79. https://hbr.org/1992/o9/the-new-society-of-organizations. Acceso 20 de mayo de 2019.

67 Cuyo texto íntegro en inglés se puede consultar en: https://www.eurashe.eu/library/modernisingphe/Bologna_1999_Bologna-Declaration.pdf Acceso 20 de mayo de 2019. En castellano en "La integración del sistema universitario español en el Espacio Europeo de Enseñanza Superior. Documento-Marco", Ministerio de Educación, Cultura y Deporte, Febrero 2003, 17-19, 17. Acceso 20 de mayo de 2019.

68 Sánchez-Agesta, "La Universidad...”, 232.

69 Cuya obra fundamental, en esta dirección, recogemos en la nota 5. 
Tal propuesta encontraría seguimiento en un reducido pero prestigioso sector de la doctrina que ha trazado una estela que podría resultar conveniente continuar y desarrollar. Y es que en tal aproximación el planteamiento no es nuevo, sino que ya fue esgrimido principalmente y desarrollado entre otros por Riccardo Orestano, Giovanni Tarello, Antonio Padoa-Schioppa, Raoul Van Caenegem, Helmut Coing, Franz Wieacker, Paolo Grossi, Randall Lesaffer o en España el citado Alfonso García-Gallo, Rogelio Pérez-Bustamente, Romás Piña Homs, o más recientemente, Bruno Aguilera Barchet y Bart Wauters junto a Marco de Benito LLopis-Lombart $^{70}$. Nos referimos aquí a las propuestas que se proponen

70 De los cuales, sin ánimo de exhaustividad, recogemos su más significativa bibliografía en esta dirección: Riccardo Orestano, Introduzione allo studio storico del diritto romano (Torino: librisaggi, 1953) y en edición revisada Introduzione allo studio del diritto romano (Bologna: Il Mulino, 1987); Giovanni Tarello, Storia della cultura giuridica moderna (Bologna: Il Mulino, 1976); Antonio PadoaSchioppa, Storia del diritto in Europa. Dall Medioevo all'età contemporánea (Bologna: Il Mulino, 2007), $7^{\text {a }}$ Edición 2016 la cual está también traducida a inglés (Cambridge: Cambridge University Press: 2017); Raoul C. Van Canegem, An Historical Introduction to Private Law (Cambridge: Cambridge University Press: 1992); Helmut Coing, Derecho Privado Europeo (Fundación Cultural del Notariado de Madrid: 1996); Franz Wieacker, Historia del Derecho...; Paolo Grossi, Europa y el Derecho (Barcelona: Crítica, 2007); De la codificación a la globalización del derecho (Pamplona: Aranzadi, 2010); Randall Lesaffer, European Legal History. A Cultural and Political Perspective (Cambridge: Cambridge University Press, 2012). Acerca de la Historia del Derecho Europeo en sus inicios a través del Max-Plank-Institut fur Europäische Rechtsgeschichte de Frankfurt dirigida por H. Coing ofrece un estudio Alfonso García-Gallo, "Cuestiones de Historiografía Jurídica" Anuario de Historia del Derecho Español 44 (1974): 743-764, 752 y ss.; Rogelio Pérez-Bustamante, Los Estados de la Unión Europea. Historia política y constitucional (Madrid: Libreria Anticuaria Jerez, 1994); Una visión histórica: La Constitución Europea de 2004 (Barcelona: Crítica, 2004); Los Consejos Europeos, 1998-2001 (Madrid: Dykinson, 2006); Historia política de la Unión Europea: 1940-1995 (Madrid: Edisofer, 2008); Román Piña Homs, Fundamentos jurídicos de Europa. Apuntes para una Historia del Derecho europeo (Palma: Edicions Cort, 2001); Bruno Aguilera Barchet, Entre Estado...; A History of Western Public Law. Between Nation and State (Heidelberg: Springer, 2015). Bart Wauters y Marco De Benito Llopis-Lombart, Historia del Derecho en Europa (Navarra: Thomson Reuters Aranzadi, 2013); The History of Law in Europe: An Introduction (Cheltenham: Edward Elgar Publishing Limited, 2017). Aparte de los citados en texto y sin ánimo de exhaustividad ofrecemos aquí una relación bibliografía de interés que comparte esta aproximación metodológica: Manlio Bellomo, L'Europa e il diritto Comune (Roma: 1983); Common Legal Past of Europe, 10oo-18oo (Washington DC: The Catholic University of America Press, 1995); Harold J. Berman, Law and Revolution. The Formation of the Western Legal Tradition (Cambridge, Massachusetts: Harvard University Press, 1983); Carlo Augusto Cannata, Historia de la ciencia jurídica europea (Madrid: Tecnos, 1996); Adriano Cavanna, Storia del diritto moderno in Europa. Le fonti e il pensiero giuridico, 2 vols. (Milano: Giuffré, 2005); John P. Dawson, The Oracles of the Law (Ann Arbor, Mich.: The University of Michigan Law School, 1968); Bruno De Witte y Caroline Forder, eds., The Common Law of Europe and the Future of Legal Education (Deventer: Häftad Engelska, 1992); Jean Gaudemet, Les naissances du Droit. Le temps, le pouvoir et la science au service du droit (Paris: Montchrestien, 2006); Martin Gebauer, Grundfragen der Europaisierung des Privatrechts (Heidelberger: Universitätsverlag. C. Winter, 1998); John Gilissen, Introduction historique au droit. Esquisse d'une histoire universelle du droit. Les sources du droit depuis le XIIIe siecle. Eléments d'histoire du droit privé (Brussels: Bruylant, 1979); Arthur S. Hartkamp, Martijn W. Hesslink, Ewoud Hondius, C Mak, Edgar Du Perron, Towards a European Civil 
el mayor empleo del método comparado. Dicho método comparado que además comenzaba a plantearse su aplicación no sólo para abordar el estudio comparado de la Historia del Derecho de las naciones entre sí, sino extendiendo su metodología a lo largo del tiempo a fin de estudiar una realidad vigente y compararla con su análoga realidad en el pasado. Naturalmente, en estas propuestas metodológicas tienen cabida una aproximación metodológica desde un prisma histórico jurídico Europeo. Tales planteamientos parecen ser el siguiente paso que debe dar la disciplina e incluso pueda verse como la urgente reacción metodológica y docente que sirva de nexo con el estudiante bilingüe de la Unión Europea. Llegados a este punto parece adecuado recordar las palabras de GarcíaGallo:

"Lo que al jurista le interesa y exige a la Historia jurídica es que ésta le dé a conocer cómo se ha desarrollado el Derecho. Al jurista, normalmente, no le interesa el Derecho como mero fenómeno cultural en el marco de cada época, sino como el ordenamiento de la vida social. Por ello, cuando se dirige a la Historia del Derecho, lo que le pide es una explicación de cómo este ordenamiento ha llegado a formarse"71.

Con visión similar en el contexto de Europa Ortega y Gasset dirá que:

"Europa tiene que aprender en la Historia, no hallando en ella una norma de lo que puede hacer - la Historia no prevé el futuro- sino que

Code (Nijmegen: Kluwer Law International, 2011); Hans Hattenhauer, Europäische Rechtsgeschichte, $4^{\text {a }}$ ed. (Heidelberg: C.F. Muller, 2004); Antonio Manuel Hespanha, Cultura jurídica europea. Síntesis de un milenio (Madrid: Tecnos, 2002); Tony Judt, A History of Europe since 1945 (Londres: Oxford University Press, 2010); John M. Kelly, A Short History of Western Legal Theory (Oxford: Oxford University Press, 1992); O. F. Robinson, T. D. Fergus, y W. M. Gordon, European Legal History (London: Oxford University Press, 2000); An Introduction to European Legal History: Sources and Institutions, $3^{\circ}$ ed. (London: Butterworths, 2000); Jan Smits, The Making of a European Private Law: Towards a Ius Commune Europaeum as a Mixed Legal System (Oxford: : Intersentia Ltd., 2002); Peter Stein, Roman Law in European History (Cambridge: Cambridge University Prees, 1999); Thomas Glyn Watkin, An Historical Introduction to Modern Civil Law (Chicago: Aldershot, 1999); Alan Watson, The Making of the Civil Law (Cambridge, Mass.: Harvard University Press, 1981); Gerhar Wesenberg y Gunter Wesener, Historia del Derecho privado moderno en Alemania y en Europa (Valladolid: Lex Nova, 1998); Heikki Pihlajamäki, Markus D. Dubber y Mark Godfrey, The Oxford Handbook of European Legal History (Oxford: Oxford University Press, 2018); John M., Zane, The Story of Law, $2^{\mathrm{a}}$ ed. (Indianapolis: Liberty Fund Inc., 1998); Reinhard Zimmermann, Roman Law, Contemporary Law, European Law. The Civilian Tradition Today (Oxford: Oxford University Press, 2001).

71 García-Gallo, "Historia, Derecho...”, 24. 
tiene que aprender a evitar lo que no hay que hacer; por tanto, a renacer siempre de sí misma evitando el pasado. Para eso nos sirve la Historia para libertarnos de lo que fue, porque el pasado es un revenant y si no se le domina con la memoria, refrescándole, él vuelve, siempre contra nosotros y acaba por estrangularnos" ${ }^{72}$.

Si entendemos que la Historia del Derecho juega un papel fundamental en la formación del jurista bien podemos concluir recordando las palabras del referenciado Guasp, al finalizar su discurso dirigido a los estudiantes y con la generosa intención de estimular su prurito universitario, les regala la siguiente reflexión:

"A mí me recuerda la ciencia del Derecho actual a una rica heredera que tiene muchos pretendientes, que todos van tras su dinero y ninguno tras su corazón. Vosotros habéis venido a la Facultad de Leyes pensando el rendimiento profesional grande que al Derecho se le puede obtener. Pero ¿No habrá entre vosotros ninguno que aspire al corazón de vuestra esposa futura? Si lo hay, y en la medida en que lo haya yo le digo: iBienvenido, amigo!"73.

\section{REFERENCIAS BIBLIOGRÁFICAS}

Aguilera Barchet, Bruno. Introducción jurídica a la Historia del Derecho, $2^{\text {a }}$ ed. Madrid: Civitas, 1996.

-. "Reflexiones sobre el concepto de Historia del Derecho", Anuario de la Facultad de Derecho. Universidad de Extremadura 9 (1991): 299378.

-. Historia y Derecho, Manual de iniciación (I). Barcelona: Hurope, 1999.

72 Ortega y Gasset, Historia como... 71.72.

73 Guasp, “Como debe estudiarse ...", D-176-177, D-184. 
-. Estado y Derecho en España. Un ensayo de historia comparada. I. Las bases: de los orígenes al año 711. Madrid-París: Instituto de Estudios Jurídicos Internacionales, 2010.

Alvarado Planas, Javier. "La Historia del Derecho ante el siglo XXI", Anuario de Historia del Derecho Español 71 (2001): 621-687.

Alvarado Planas, Javier; Dolores del Mar Sánchez González; Regina María Pérez Marcos y Jorge J. Montes Salguero. Lecciones de Historia del Derecho y de las Instituciones, T. I. Madrid: Universidad Nacional a Distancia, 2002.

Arvizu y Galarraga, Fernando de. "La enseñanza de la Historia del Derecho: reflexiones en busca de una polémica" Anuario de Historia del Derecho Español 58 (1988): 491-498.

Bloch, Marc. Introducción a la Historia. Madrid: Fondo de Cultura Económica, 1992.

Capella Hernández, Juan Ramón. "La crisis actual de la enseñanza del derecho en España”. En La enseñanza del Derecho. Seminario de Profesores de la Facultad de Derecho, dirigido por Juan José Gil Cremades, 23-42. Zaragoza: Institución Fernando el Católico, 1985.

Coing, Helmut. Las tareas del historiador del Derecho. Reflexiones metodológicas. Traducido por A. Merchan. Sevilla: Publicaciones de la Universidad de Sevilla, 1977.

-. Derecho Privado Europeo. Madrid: Fundación Cultural del Notariado de Madrid, 1996.

Dios, Salustiano de. "El Derecho y la realidad social: reflexiones en torno a la Historia de las Instituciones”. Historia, Instituciones y Documentos 3 (1976): 189-222.

Escudero, José Antonio. "Derecho y tiempo: dogmática y dogmáticos”. Anuario de Historia del Derecho Español 40 (1970): 269-286. 
-. Curso de Historia del Derecho, Fuentes e Instituciones Político-administrativas. Madrid: Edisofer, 2003.

García-Gallo, Alfonso. "Historia, Derecho e Historia del Derecho”. Anuario de Historia del Derecho Español 23 (1953): 5-36.

-. "Cuestiones de Historiografía Jurídica". Anuario de Historia del Derecho Español 44 (1974): 743-764.

-. Manual de Historia del Derecho español, Tomo I. Madrid: A.G.E.S.A., 1971.

García Garrido, Manuel Jesús y Eugenio, Francisco. Estudios de Derecho y Formación de Juristas. Madrid: Dykinson, 1988.

Gibert, Rafael. "Concepto de la Historia del Derecho español”. Anuario de la Facultad de Derecho de la Universidad de Extremadura 4 (1947): 305-344.

Gómez de la Serna, Pedro. Prolegómenos del Derecho. Madrid: Librería de Sánchez, 1887.

Grossi, Paolo. Europa y el Derecho. Barcelona: Crítica, 2007.

-. De la codificación a la globalización del derecho. Pamplona: Aranzadi, 2010.

Lalinde Abadía, Jesús. "Hacia una Historia paralógica del Derecho”. Historia, Instituciones, Documentos 4 (1977): 317-353.

Meilán Gil, José Luis. Los planes universitarios de enseñanza en la España contemporánea. Madrid, 1970.

Navarro Valls, Rafael. "Principios éticos y responsabilidad en el ejercicio de la función docente”. En La Universidad y las profesiones jurídicas. Deontología, Función Social y Responsabilidad, 107-122. Madrid: Fundación Central Hispano, 1998.

Guasp, Jaime. "Como debe estudiarse el Derecho”. Anales de la Universidad de Murcia 16/3-4 (1957-1958): 173-184. 
Orestano, Riccardo. Introduzione allo studio storico del diritto romano. Torino, 1953. En edición revisada Introduzione allo studio del diritto romano. Bologna: Il Mulino, 1987.

Ortega y Gasset, José. Historia como sistema. Madrid: Revista de Occidente, 1966.

Padoa-Schioppa, Antonio. Storia del diritto in Europa. Dall Medioevo

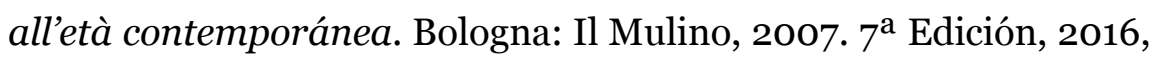
versión en inglés por Cambridge University Press, en 2017.

Pérez-Prendes y Muñoz de Arraco, José Manuel. Curso de Historia del Derecho Español. Madrid: Universidad Complutense de Madrid, 1989.

-. Historia del Derecho Español, Vol. 1. Madrid: Universidad Complutense, 2004.

Sánchez, Galo. Curso de Historia del Derecho. Apuntes. Madrid: Editorial Reus, 1975 .

Tarello, Giovanni. Storia della cultura giuridica moderna. Bologna: Il Mulino, 1976.

Tomás y Valiente, Francisco. Manual de Historia del Derecho español. Madrid: Tecnos, 1979.

Koschaker, Paul. Die Krise des römischen Rechts und die romantistiche Rechtvissenschaft. München, Berlin: Beck, 1938.

-. Europa und das römische Recht. Traducido por J. Santa Cruz. Madrid, 1955 .

Vallet de Goytisolo, Juan B. Estudios sobre fuentes del Derecho y método jurídico. Madrid: Montecorvo, 1982.

Wieacker, Franz. Historia del Derecho privado de la Edad Moderna. Granada: Comares, 2000. 


\section{Gabriela Cristina Cobo del Rosal Pérez}

Área de Historia del Derecho

Departamento de Ciencias de la Educación, Lenguaje, Cultura y Artes, Ciencias Historico-Jurídicas y Humanísticas y Lenguas Modernas Universidad Rey Juan Carlos Paseo de los Artilleros s/n 28032 - Vicálvaro - Madrid gabriela.cobodelrosal@urjc.es https://orcid.org/o0oo-0001-8515-4743 